\title{
Investigation of the effect of nozzle design on rheological bioprinting properties using computational fluid dynamics
}

\author{
Isabela Poley Magalhães ${ }^{1,2}$, Patrícia Muniz de Oliveira ${ }^{2}$, \\ Janaína Dernowsek ${ }^{3}$,Estevam Barbosa Las Casas ${ }^{2}$, \\ Marina Spyer Las Casas ${ }^{2}$
}

\footnotetext{
${ }^{1}$ Bioengineering Laboratory - LABBIO - PPGMEC/EE/UFMG - 6627, Presidente Antônio Carlos Avenue, CEP: 31270 901, Belo Horizonte, Minas Gerais, Brazil.

${ }^{2}$ Biomechanical Engineering Group - MECBIO - PROPEES/EE/UFMG - 6627, Presidente Antônio Carlos Avenue, CEP: 31270-901, Belo Horizonte, Minas Gerais, Brazil

${ }^{3}$ Information Technology Center Renato Archer - Dom Pedro I Highway (SP-65), km 143.6, CEP: 13069-901, Campinas, São Paulo, Brazil.

e-mail: munizpatricia@outlook.com.br, poley@ufmg.br, jdernows@cti.gov.br, estevam.lascasas@gmail.com, marinalas@yahoo.com.br
}

\begin{abstract}
Bioprinting is the utilization of techniques derived from three-dimensional printing to generate complex biological structures which may replace natural tissues or organs. It employs high spatial resolution deposition of different cell types, growth factors and biomaterials. Those together form bioinks, which are the bioprinting inputs, analogously to conventional inks with regard to inkjet printing. In extrusion bioprinting, continuous bioink filaments are deposited layer by layer on a surface by means of an extruder nozzle, employing the displacement of a piston or pneumatic pressure. If mechanical stresses applied on a cell membrane exceed a critical value, which depends on the cell type, the cell membrane may disrupt. Computational fluid dynamics (CFD) simulations of the bioink extrusion were done to evaluate shear stresses caused by the internal pressure of extruder nozzles during bioprinting. Different three-dimensional conical nozzle designs were tested by varying angles of convergence, lengths, input diameters and output diameters of the nozzles. The powerlaw model, with constants $\mathrm{k}=109.73 \mathrm{~Pa} \cdot \mathrm{s}^{0,154}$ and $\mathrm{n}=0.154$, was used to describe the expected nonNewtonian behavior of the bioink. Shear stresses and shear rates were evaluated for each nozzle design considering different pressures or velocities as boundary conditions at the nozzle entrance. The maximum wall shear stress value on each different nozzle varied between 1,038 $\mathrm{Pa}$ and 4,915 $\mathrm{Pa}$. The results indicated which details of nozzle geometry are most relevant in order to optimize bioprinting. The best conditions for bioink rheology were also evaluated to ensure good printability and high cell viability.
\end{abstract}

Keywords: bioink, bioprinting, biofabrication, 3D printing, CFD.

\section{INTRODUCTION}

Tissue and organ transplantation can extend and improve quality of life, but transplanted patients require use of immunosuppressive drugs for the rest of their lives. This justifies the resistance against tissue and organ transplantation for the replacement of non-vital organs and tissues such as uterus, ovaries, ear cartilage or articular cartilage, even though their absence negatively impacts the wellness, self sufficiency, self-esteem or aspirations of patients. Special care and medication are also needed in cases where the patient receives a synthetic prosthesis, such as the metal implants of a knee arthroplasty, which does not offer a definitive solution and is still subjected to the possibility of rejection, anatomical inadaptability and mechanical failures. The inability to control rejection motivates the search of alternatives to conventional tissue and organ transplantation.

The purpose of tissue engineering is to create, from biomaterials and stem cells of recipient patients, substituents that maintain the structure and function of tissues or organs to be replaced in order to eliminate all difficulties that arise from transplantation. Recent advances in stem cells, biomaterials, and biofabrication have already been made towards the creation of bioartificial blood vessels, airways, heart valves, bladders, kidneys and livers [1].

One promising area of tissue engineering is bioprinting, which aims to use stem cells and the princi- 
ples of additive manufacturing to biofabricate rejection-free tissues and organs. Bioprinting uses computercontrolled 3D printing devices to precisely deposit bioinks, which comprises cells, growth factors, biocompatible hydrogels or other biomaterials. The cartridge system is similar to that of conventional inkjet printing, so many bioinks containing different cell types can be loaded into different cartridges and deposited as commands are sent by a computer-aided design (CAD) system to create anatomically correct structures[2, 3].

Extrusion bioprinting systems deposit continuous bioink filaments by means of an extruder nozzle employing pneumatic pressure or syringe pump. The amount of deposited bioink can be adjusted by controlling the pressure or piston displacement. The three-dimensional structure is created by stacking in layers many two-dimensional patterns traced with the filaments. The extrusion bioprinting method, compared to other bioprinting methods such as the jetting-base one, allows the use of a wider range of biomaterials by being compatible with higher viscosities. Another advantage of the extrusion method is that the viability of cell survival after extrusion deposition is considered high, greater than $90 \%[3,4]$.

Cartilages are usually chosen as a starting point for bioprinting studies because they are simpler compared to other tissues due to their lower vascularization and enervation. These intrinsic properties, which enable durability and long-lasting function, related to low cell activity, also hinder regeneration. This makes replacement with bioprinted substituents very desirable. There is also a demand to treat osteoarthritis, the most common joint disease worldwide, which is "a major source of pain, disability, and socioeconomic cost" $[5]$.

Articular cartilaginous tissues act as a cushion between the bones, providing a smooth and gliding surface for joint motion. Osteoarthritis is a condition where the cartilage between the bones is thinned and sometimes worn out. This leads to exposure of the bone ends, causing friction and erosion, and consequent bone damage, movement restrictions and intense pain [6,7]. Around $10 \%$ of men and $18 \%$ of women over 60 years suffer from osteoarthritis [8].

The conventional treatment for osteoarthritis is arthroplasty, which is the replacement of the joint with a synthetic one often made from a stainless-steel alloy and polyethylene [7]. However, the prosthesis is never quite as good as the natural joint. Some movement restrictions remain after surgery, and the lifespan of the artificial prosthesis is limited [5].

The focus of this study was the optimization of extruder nozzle design by means of computational simulations of the extrusion bioprinting process for cartilaginous tissues. This optimization is part of the customization of a bioprinter for cartilaginous tissues, in which different bioink formulations may be prospectively tested.

Simulations through computational fluid dynamics (CFD) are helpful to test rheological properties of bioinks in order to avoid clogging of real printing nozzles. In case of cell-laden bioinks, simulations also help avoiding losses of a large number of cells. Those losses may occur because, in bioprinting processes, cells are exposed to shear stresses due to the velocity gradient in the thin printing needle. If the stresses exceed a certain value, cell membranes may disrupt.

\section{MATERIALS AND METHODS}

Rhinoceros ${ }^{\mathrm{TM}} 5.0$ (McNeel North America, Seattle, WA) was employed as a CAD software to generate many three-dimensional models of extruder nozzle designs, varying convergence angles $\left(\alpha_{1}, \alpha_{2}\right)$ both in needle hub and shaft, needle hub length (l), shaft length (L), and exit diameters $\left(\mathrm{d}_{1}, \mathrm{~d}_{2}\right)$ both in needle hub and shaft, as shown in Figure 1. The inlet diameter (D) was fixed as $10 \mathrm{~mm}$ for all nozzles. Only the flow domains for each nozzle were modeled. 


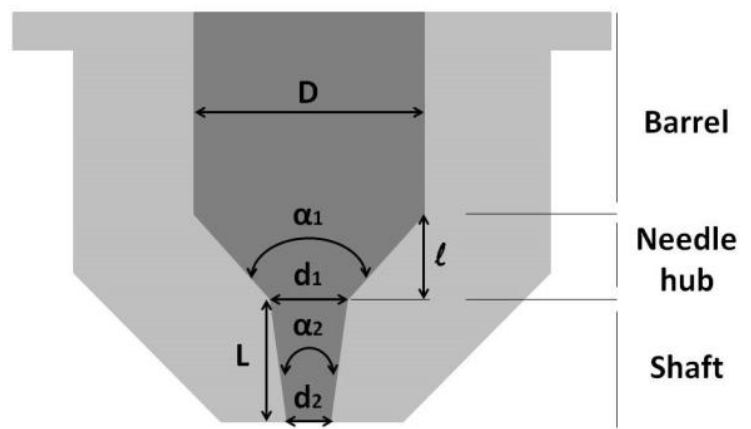

Figure 1: Geometric structure of a bioprinting nozzle with its detailed regions (barrel, needle hub and shaft) and parameters (convergence angles $\alpha_{1}$ and $\alpha_{2}$, length 1 , needle length $\mathrm{L}$, inlet diameter $\mathrm{D}$, and exit diameters $\mathrm{d}_{1}$ and $\mathrm{d}_{2}$ ).

The design parameters were set for each nozzle model as presented in Table 1.

Table 1: Design parameters of the nozzle models.

\begin{tabular}{l|l|l|l|l|l|l}
\hline NOZZLE & $\boldsymbol{\alpha}_{\mathbf{1}}$ (DEGREES) & $\boldsymbol{\alpha}_{\mathbf{2}}$ (DEGREES) & $\mathbf{I}(\mathbf{m m})$ & $\mathbf{L}(\mathbf{m m})$ & $\mathbf{d}_{\mathbf{1}}(\mathbf{m m})$ & $\mathbf{d}_{\mathbf{2}}(\mathbf{m m})$ \\
\hline 1 & 43.60 & 4.98 & 10.0 & 20.0 & 2.00 & 0.26 \\
\hline 2 & 43.60 & 4.55 & 10.0 & 20.0 & 2.00 & 0.41 \\
\hline 4 & 48.46 & 2.29 & 10.0 & 10.0 & 1.00 & 0.60 \\
\hline 5 & 48.46 & 1.15 & 10.0 & 20.0 & 1.00 & 0.60 \\
\hline 6 & 48.46 & 0.57 & 10.0 & 40.0 & 1.00 & 0.60 \\
\hline 8 & 55.96 & 2.01 & 8.0 & 20.0 & 1.50 & 0.80 \\
\hline 9 & 22.62 & 3.44 & 20.0 & 20.0 & 2.00 & 0.80 \\
\hline
\end{tabular}

The geometric models were then imported into ANSYS FLUENT ${ }^{\circledR} 18.2$ (ANSYS, Inc., Canonsburg, PA), a software based on the finite volume element method, to perform CFD simulations. The finite element mesh established for the models had between 11,000 and 15,000 elements.

The rheological characteristics of the extruded fluid were considered to be the same described by DHARMADASA [9[9], which has modeled a non-Newtonian bioink that combines shear thinning viscous properties for good printability and fast cross-linking properties to assure sufficient stiffness for the bioprinted material to hold its shape after printing. The bioink was thus modeled as a fluid having a density equal to $998.2 \mathrm{~kg} \cdot \mathrm{m}^{-3}$ and whose viscous behavior was described by the power-law viscosity model for nonNewtonian fluids, given by Equation 1.

$$
\eta=k \cdot \gamma^{n-1} e^{T 0 / T}
$$

In Equation 1, $\eta$ is the viscosity, $\gamma$ is the shear rate, and $T$ is the temperature. The bioink viscosity was assumed to be independent from temperature, thus $T_{0}=0$. The adopted consistency index $k$ was 109.73 $\mathrm{Pa} \cdot \mathrm{s}^{0,154}$, and the deviation from the Newtonian model, $n$ was assumed to be 0.154 .

Shear stresses and shear rates were evaluated for different nozzle designs considering 0.2 MPa as a pressure boundary condition at the nozzle inlet, a similar value to the ones found in literature [10,11]. The fixed inlet pressure results in different velocities depending on the nozzle design. The effect of other values of inlet pressure is further discussed. The outlet boundary condition was set to be the standard atmospheric pressure, 101,325 $\mathrm{Pa}$.

\section{RESULTS}

The results of velocities and wall shear stresses caused by the flow inside printing nozzles during bioprinting are presented on Table 2. The maximum wall shear stress values varied between 1,038 $\mathrm{Pa}$ and 4,915 $\mathrm{Pa}$ for each different nozzle on the flow direction $\mathrm{Z}$. The wall shear contour plots for all the nozzles are shown on 
the Appendix.

Table 2: Wall shear data for all modeled nozzles using inlet pressure $0.2 \mathrm{MPa}$ as boundary condition.

\begin{tabular}{l|l|l|l|l|l}
\hline NOZZLE & $\begin{array}{l}\text { INLET VELOCITY } \\
\text { W (m/s) }\end{array}$ & $\begin{array}{l}\text { WALL SHEAR } \\
(\mathbf{P a})\end{array}$ & $\begin{array}{l}\text { WALL SHEAR Z } \\
(\mathbf{P a})\end{array}$ & $\begin{array}{l}\text { MAXIMUM } \\
\text { WALL SHEAR } \\
(\mathbf{P a})\end{array}$ & $\begin{array}{l}\text { MAXIMUM } \\
\text { WALL SHEAR Z } \\
(\mathbf{P a})\end{array}$ \\
\hline 1 & 0.0110274 & 288.575 & 285.988 & $1,331.29$ & $1,331.07$ \\
\hline 2 & 0.028907 & 322.025 & 320.047 & $1,251.85$ & $1,251.66$ \\
\hline 3 & 0.0658549 & 347.788 & 343.779 & $1,142.28$ & $1,142.23$ \\
\hline 5 & 0.0440651 & 397.227 & 393.904 & $1,040.62$ & $1,040.61$ \\
\hline 6 & 0.242672 & 627.174 & 620.65 & $4,927.33$ & $4,914.97$ \\
\hline 8 & 0.149992 & 433.154 & 422.233 & $1,437.47$ & $1,435.76$ \\
\hline 9 & 0.112852 & 394.424 & 393.527 & $1,127.92$ & $1,127.84$ \\
\hline & 0.177974 & 438.502 & 437.545 & $1,101.82$ & $1,101.55$ \\
\hline
\end{tabular}

\section{DISCUSSION}

According to BLAESER et al. [12], shear stresses below $4 \mathrm{kPa}$ provide satisfactory cell viability of $94 \%$ for human mesenchymal stem cells (hMSCs). Only nozzle 5 presented maximum wall shear above that value for an inlet pressure of $0.2 \mathrm{MPa}$. Thus, it may be possible to use higher inlet pressures for the other nozzle designs and to choose nozzles among the smallest exit diameters (like nozzle 1, nozzle 2 and nozzle 4 ) in order to improve printing resolution.

The effects of the convergence angle and the exit diameter indicated that design of the shaft region is decisive when optimizing bioprinting nozzles to balance printing resolution and cell viability. Among the nozzles with the smallest exit diameters, nozzle 5 presents the smallest convergence angle of the shaft, leading to the highest wall shear stresses.

The highest velocities were observed in nozzle 5 and nozzle 9. The latter presents the bigger exit diameter, which leads to the worst printing resolution. If it is desirable to optimize print speed without hampering resolution and cell viability, one can consider using nozzle 5 with lower values of inlet pressure.

Similarly to most biological tissues, bioinks need to have viscoelastic nature. Consequently, their material properties like elastic moduli and viscosity cannot be constants. The stiffness of the bioprinted material has important implications for cell development and differentiation [13], and has to be similar to that of the natural tissue, specially for cartilages. On the other hand, bioinks generally need to have low viscosities in order to pass through printing nozzles. Shear thinning properties, like those described by DHARMADASA [9], must provide the expected change on the rheological properties.

\section{CONCLUSIONS}

From CFD simulations of bioink flow along different nozzle designs, optimal conditions for nozzle geometry could be established, in order to grant satisfactory printability. Most models have presented shear stresses limited to values that would assure sufficient cell viability, considering the fixed inlet pressure of $0.2 \mathrm{MPa}$. The results provided a good qualitative comparison between the different nozzle designs, but accurate quantitative results would require a mesh refinement study, which is proposed as future work. Besides that, the computer simulations have yet to be compared with experimental data from dimensional analysis in order to be validated, although they have already helped narrowing the number of future experiments to be done. For cartilaginous tissues, the bioink must have shear thinning properties for good printability, or has to be polymerized just after the extrusion process to achieve stiffness similar to that of natural tissues.

\section{ACKNOWLEDGMENTS}

The authors are grateful to the Renato Archer Center for Technology Information, the Biomechanical Engineering Group (BIOMEC) of UFMG, and the Bioengineering Laboratory (LABBIO) of UFMG for their sup- 
port.

\section{BIBLIOGRAPHY}

[1] MURPHY, S. V., ATALA, A. "Organ engineering - combining stem cells, biomaterials, and bioreactors to produce bioengineered organs for transplantation”. Bioessays, vol. 35, pp. 163-172, 2013.

[2] MURPHY, S. V., SKARDAL, A., ATALA, A. "Evaluation of hydrogels for bio-printing applications". Journal of Biomedical Materials Research A, v. 10, issue 1, pp. 272-284, 2012.

[3] SEOL, Y. J., KANG, H. W., LEE, S. J., et al., "Bioprinting technology and its applications”. European Journal of Cardio-Thoracic Surgery, pp. 1-7, 2014.

[4] KANG, H. W., LEE, S. J., KO, I. K., et al., “A 3D bioprinting system to produce human-scale tissue constructs with structural integrity”, Nature Biotechnology, pp. 1-11, 2016.

[5] GLYN-JONES, S., PALMER, A. J. R., AGRICOLA, R., et al., “Osteoarthritis”, Lancet, vol. 386, pp. 376-387, 2015.

[6] ARTHRITIS FOUNDATION. Available in: http://www.arthritis.org/aboutarthritis/types/osteoarthritis/what-is-osteoarthritis.php. Acessed in June 16 th 2017.

[7] MANDAL, A. CARTILAGE DISEASES. Available in: http://www.news-medical.net/health/CartilageDiseases.aspx. Acessed in June 16th 2013.

[8] WOOLF, A. D., PFLEGER, B. "Burden of major musculoskeletal conditions", Bull World Health Organ, v. 81, pp. $646-656,2003$.

[9] DHARMADASA, V. "Investigation of cell-viability in the bioprinting process", Degree M.Sc., Kth Royal Institute, Stockholm, 2016.

[10] DALY, A. C., CRITCHLEY, S. E., RENCSOK, E. M., et al., “A comparison of different bioinks for 3D bioprinting of fibrocartilage and hyaline cartilage", Biofabrication, vol. 8, 2016.

[11] LEE, J. S., HONG, J. M., JUNG, J. W., et al., "3D printing of composite tissue with complex shape applied to ear regeneration". Biofabrication, vol. 6, 2014.

[12] BLAESER, A., CAMPOS, D. F. D., PUSTER, U., et al., "Controlling Shear Stress in 3D Bioprinting is a Key Factor to Balance Printing Resolution and Stem Cell Integrity". Advanced Healthcare Materials, vol. 5, pp. 326-333, 2016.

[13] DISCHER, D. E., JANMEY, P., WANG, Y. L. "Tissue Cells Feel and Respond to the Stiffness of Their Substrate", Science, v. 310, n. 5751, pp. 1139-1143, 2005.

\section{ORCID}

Patrícia Muniz de Oliveira Isabela Magalhães Poley

Estevam Barbosa Las Casas

Marina Spyer Las Casas

Janaina Dernowsek https://orcid.org/0000-0003-4489-9524

https://orcid.org/0000-0002-7456-9262

https://orcid.org/0000-0001-6078-8408

https://orcid.org/0000-0003-2261-5877

https://orcid.org/0000-0002-1909-1868 


\section{APPENDIX}

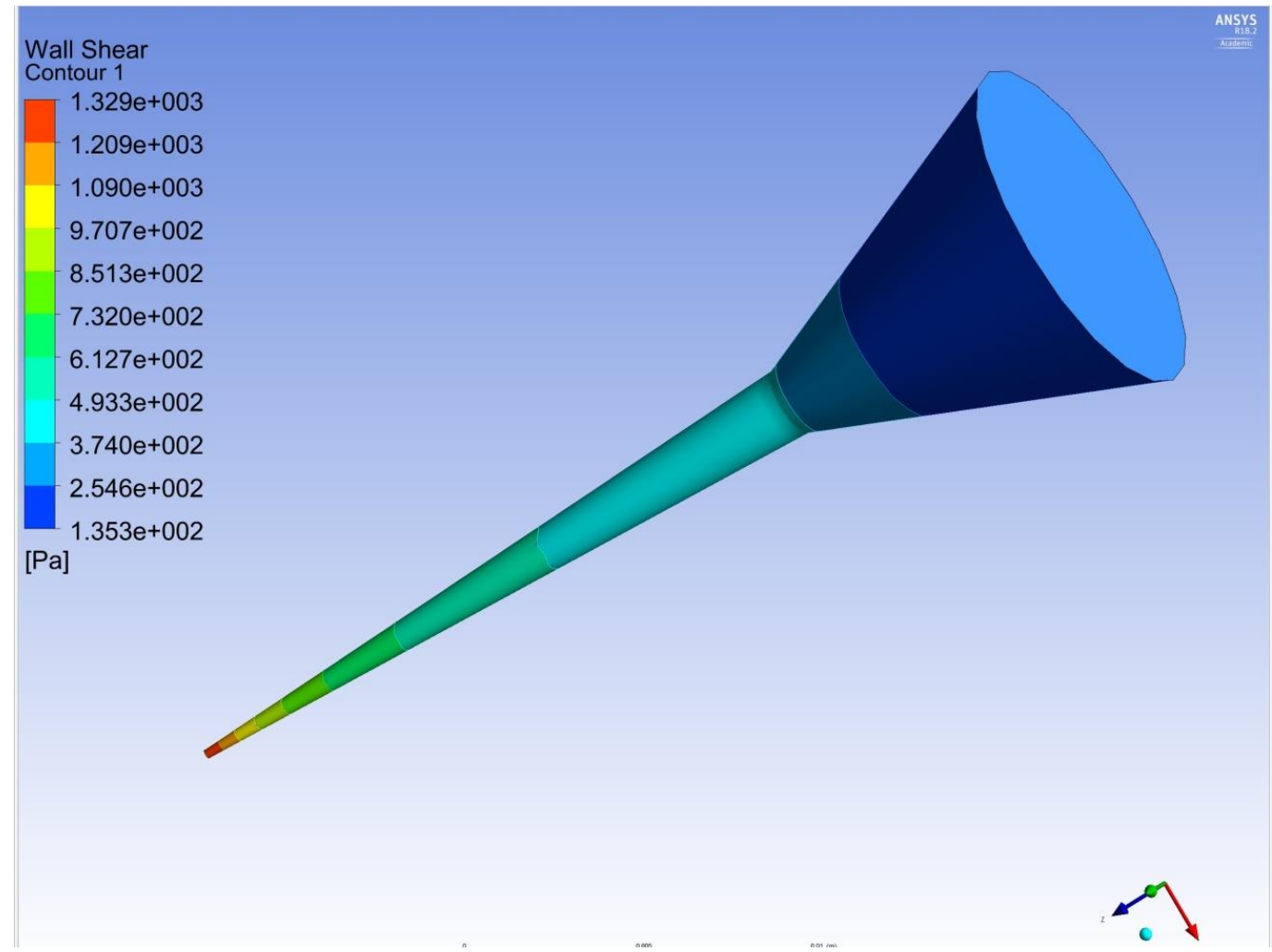

Figure 2: Wall shear contour plot for nozzle 1.

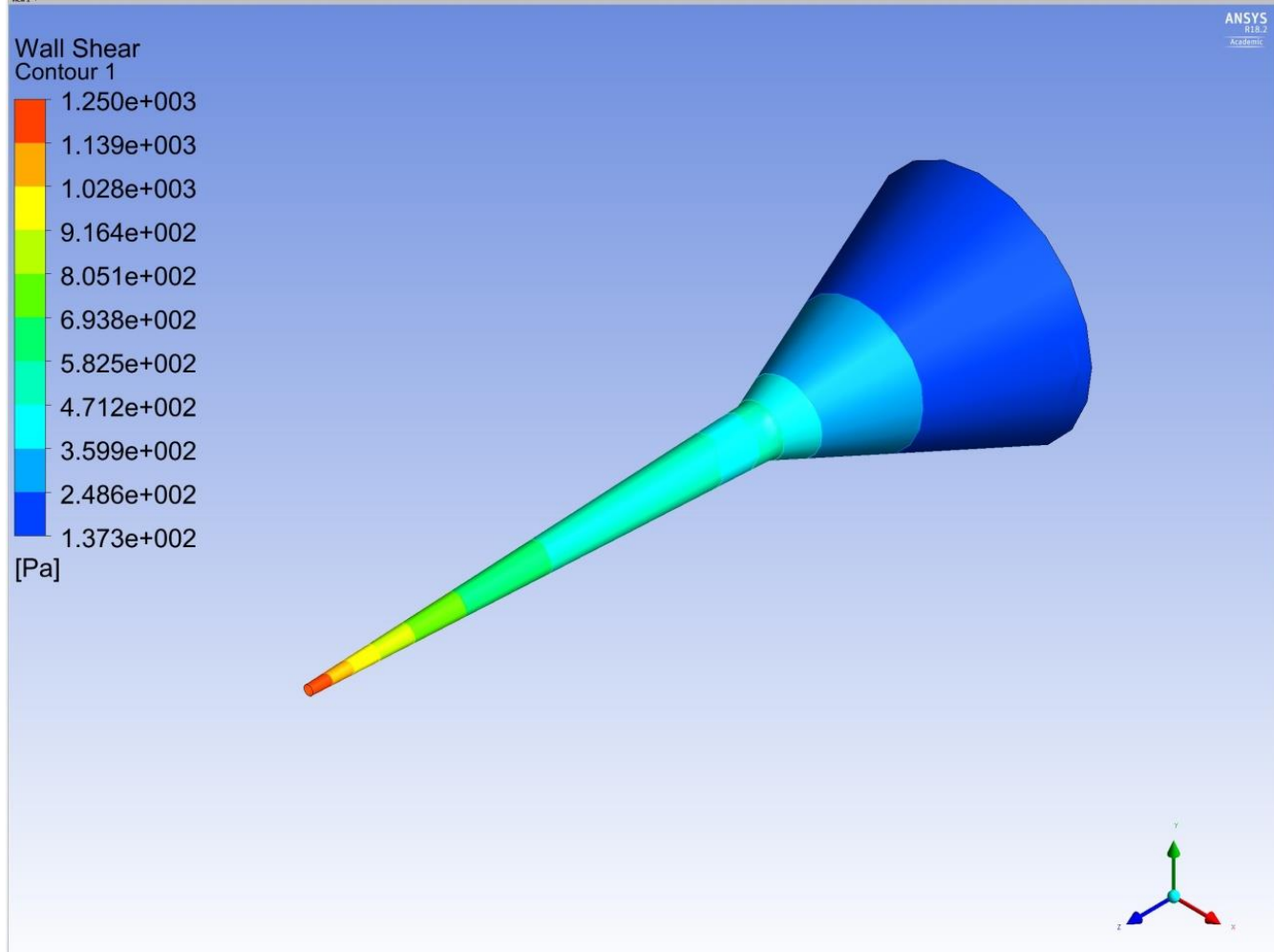

Figure 3: Wall shear contour plot for nozzle 2. 


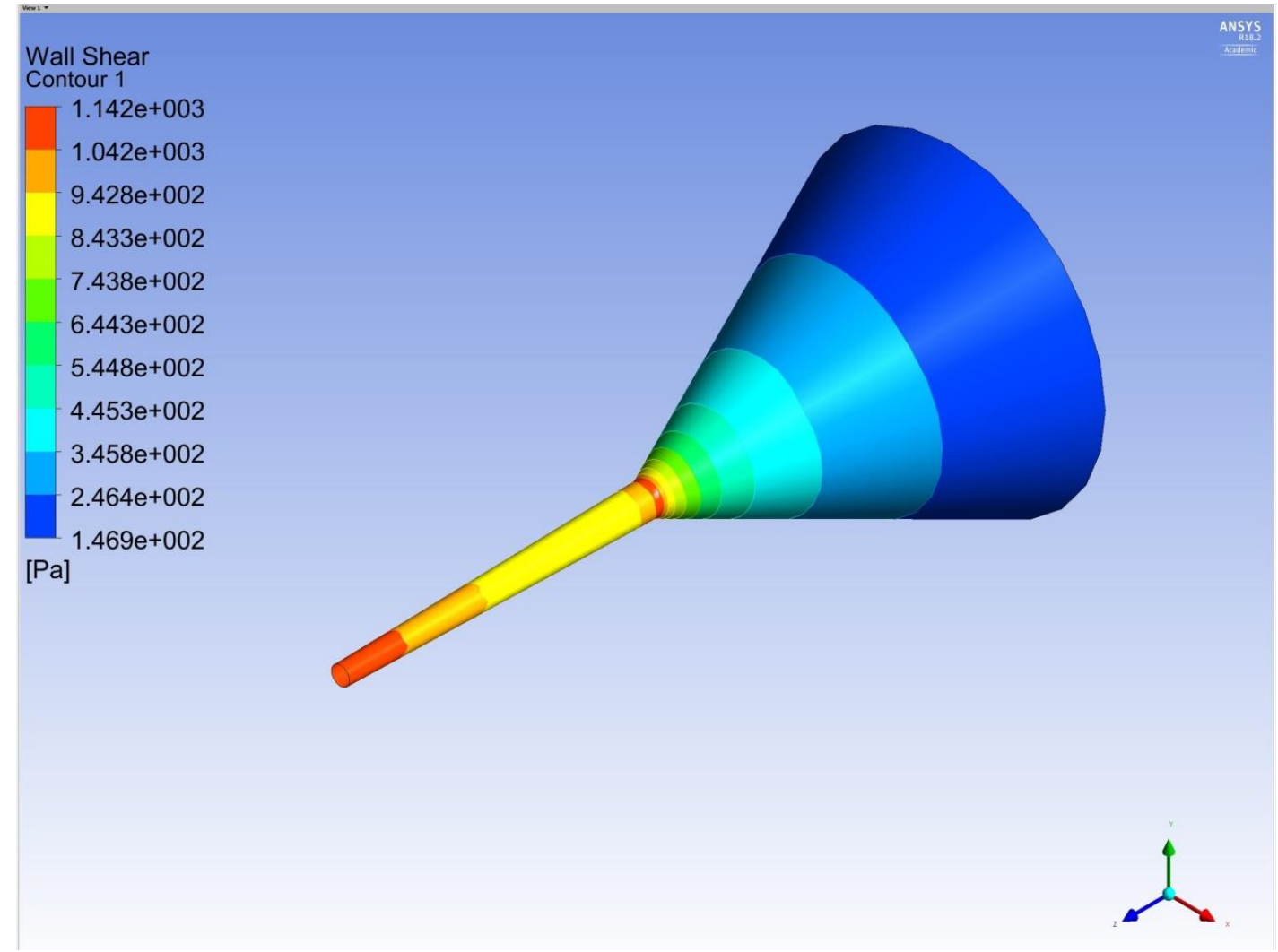

Figure 4: Wall shear contour plot for nozzle 3.

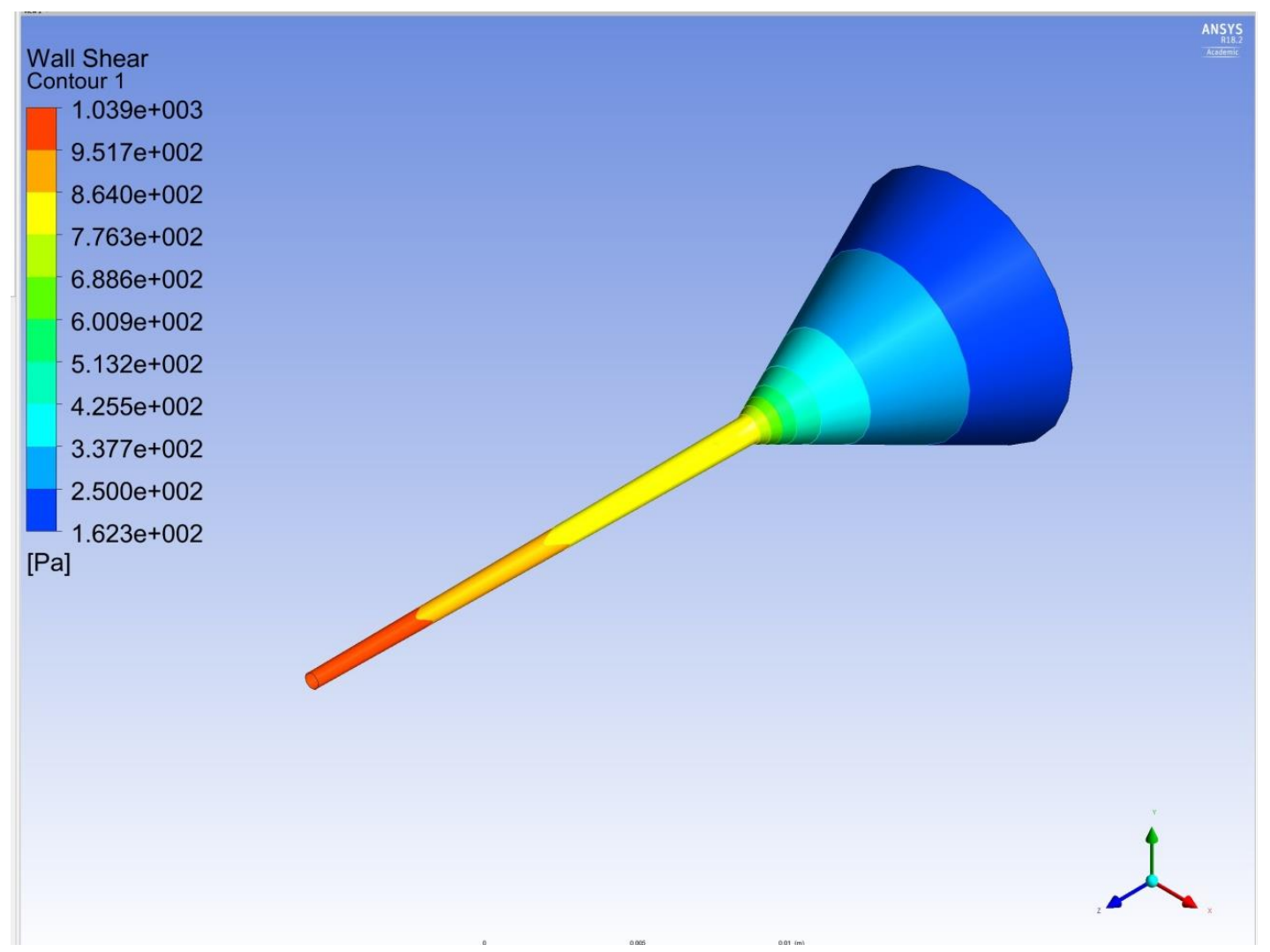

Figure 5: Wall shear contour plot for nozzle 4. 


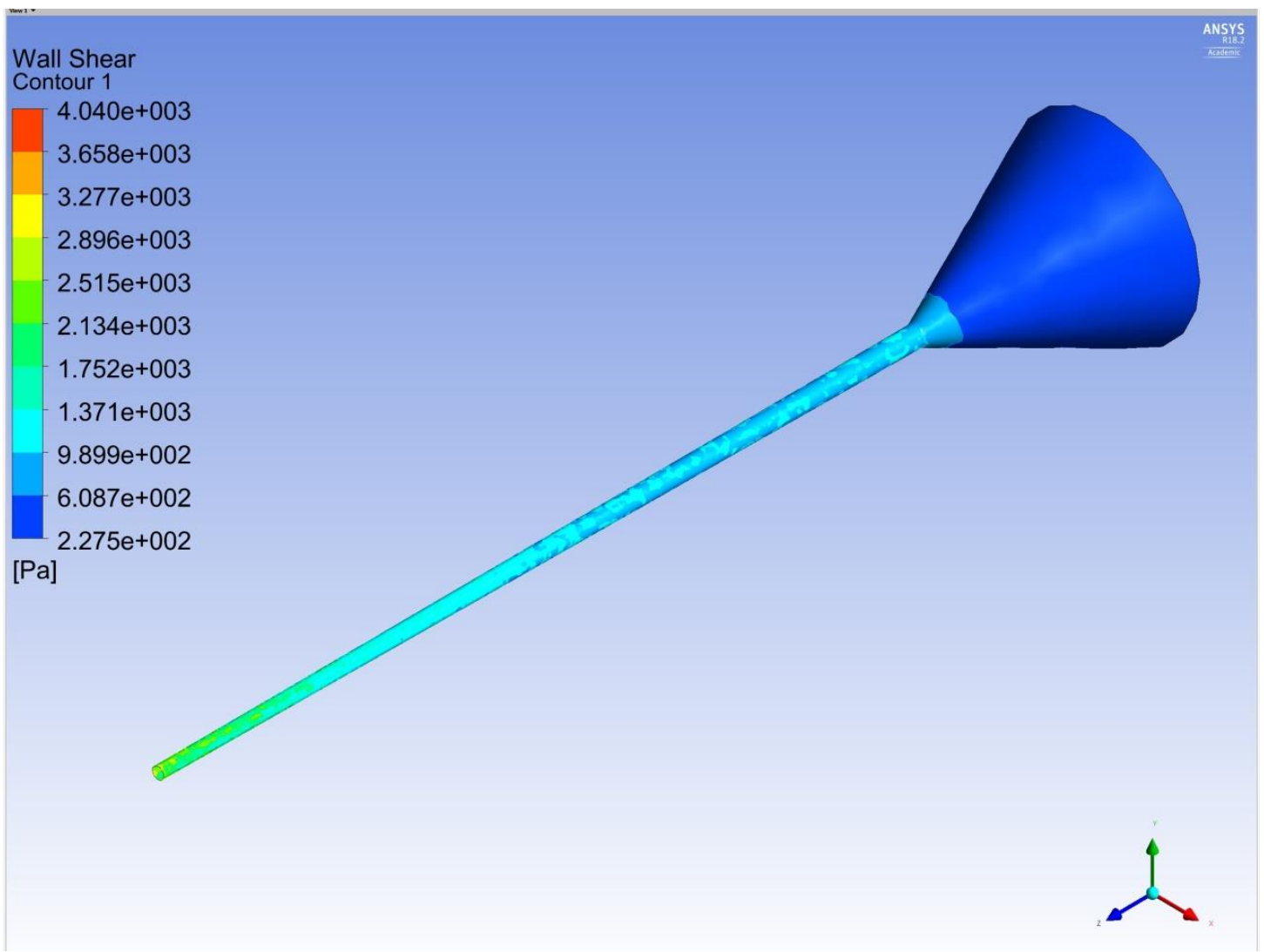

Figure 6: Wall shear contour plot for nozzle 5.

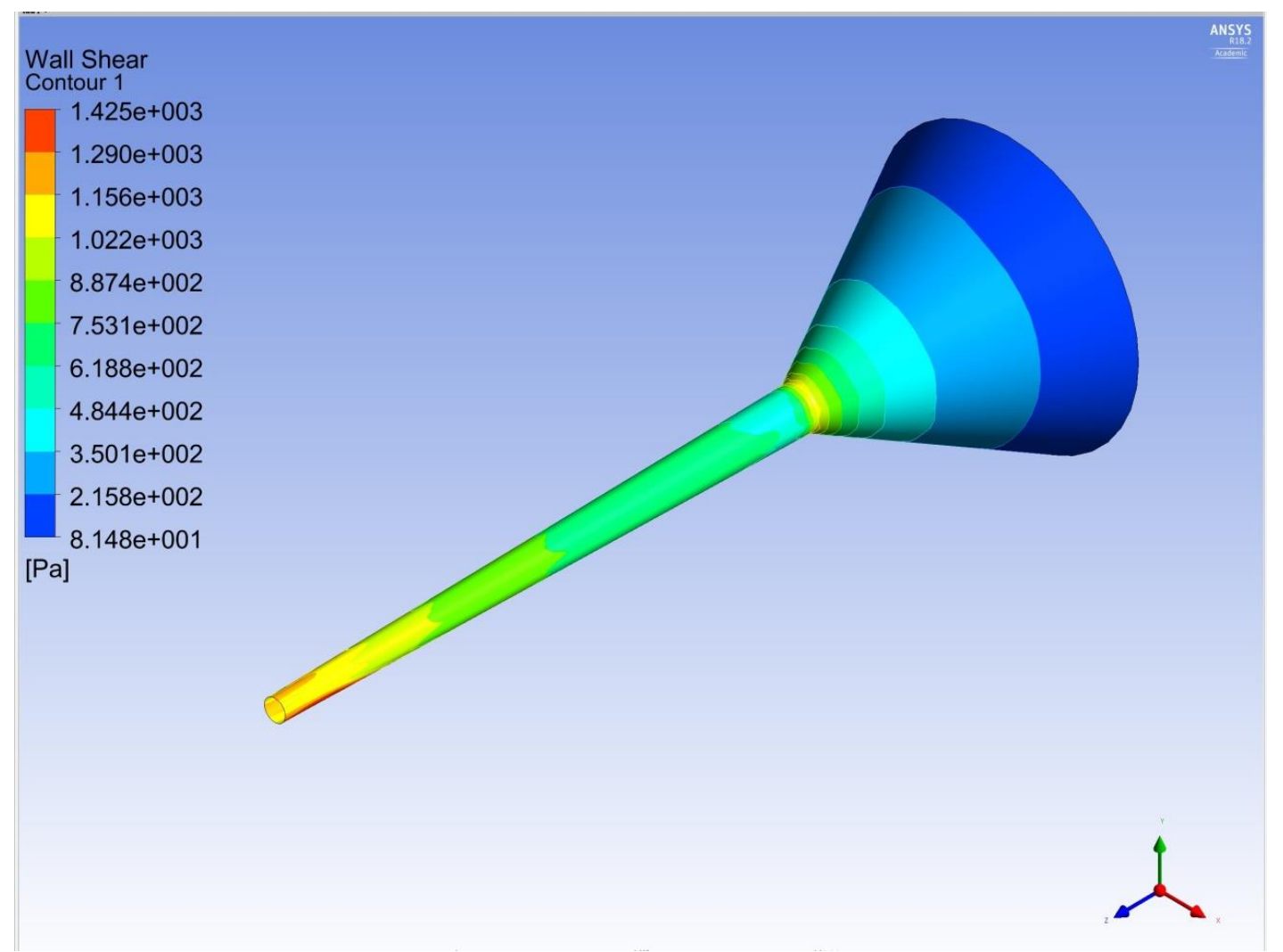

Figure 7: Wall shear contour plot for nozzle 6. 


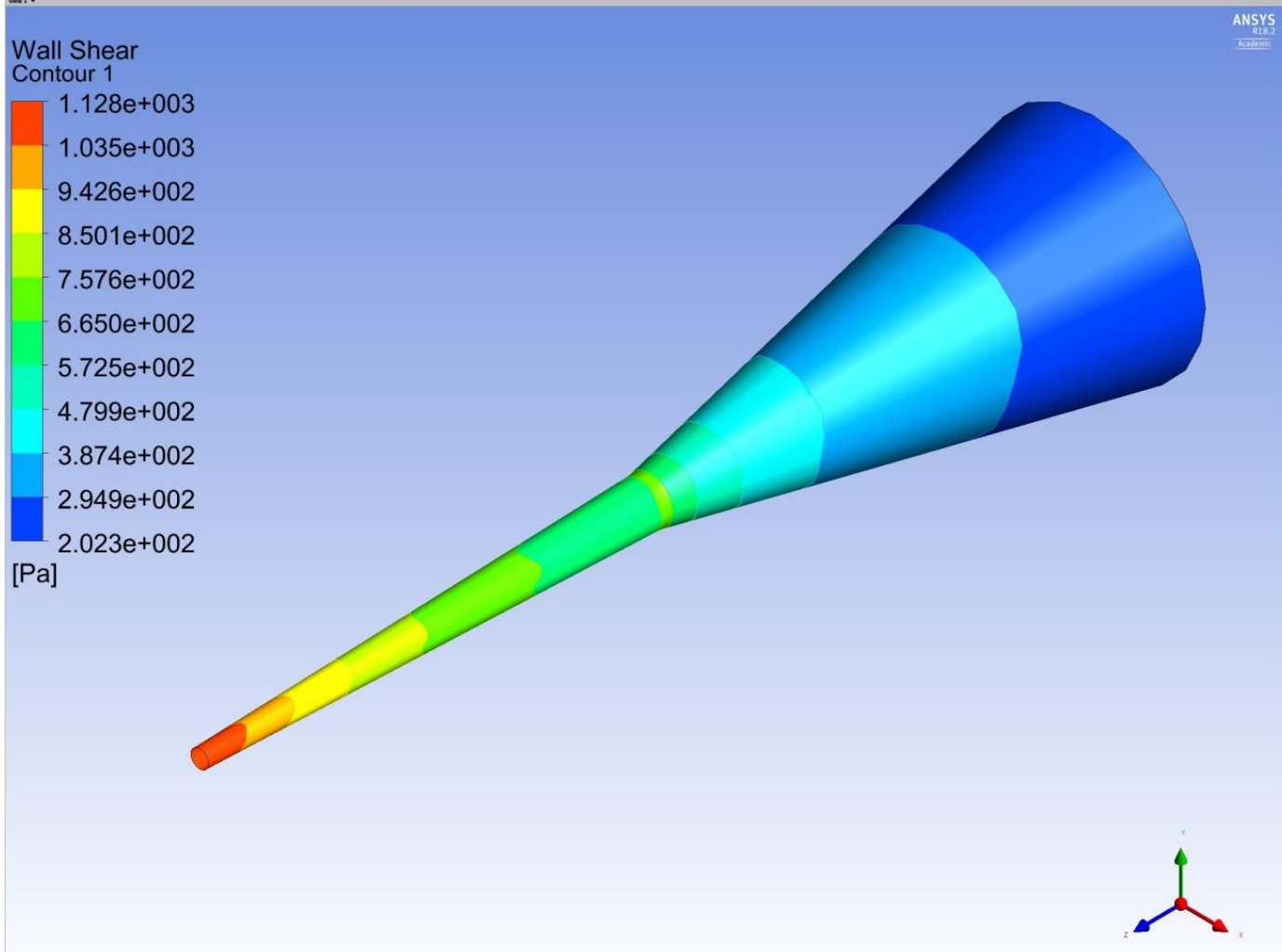

Figure 8: Wall shear contour plot for nozzle 7.

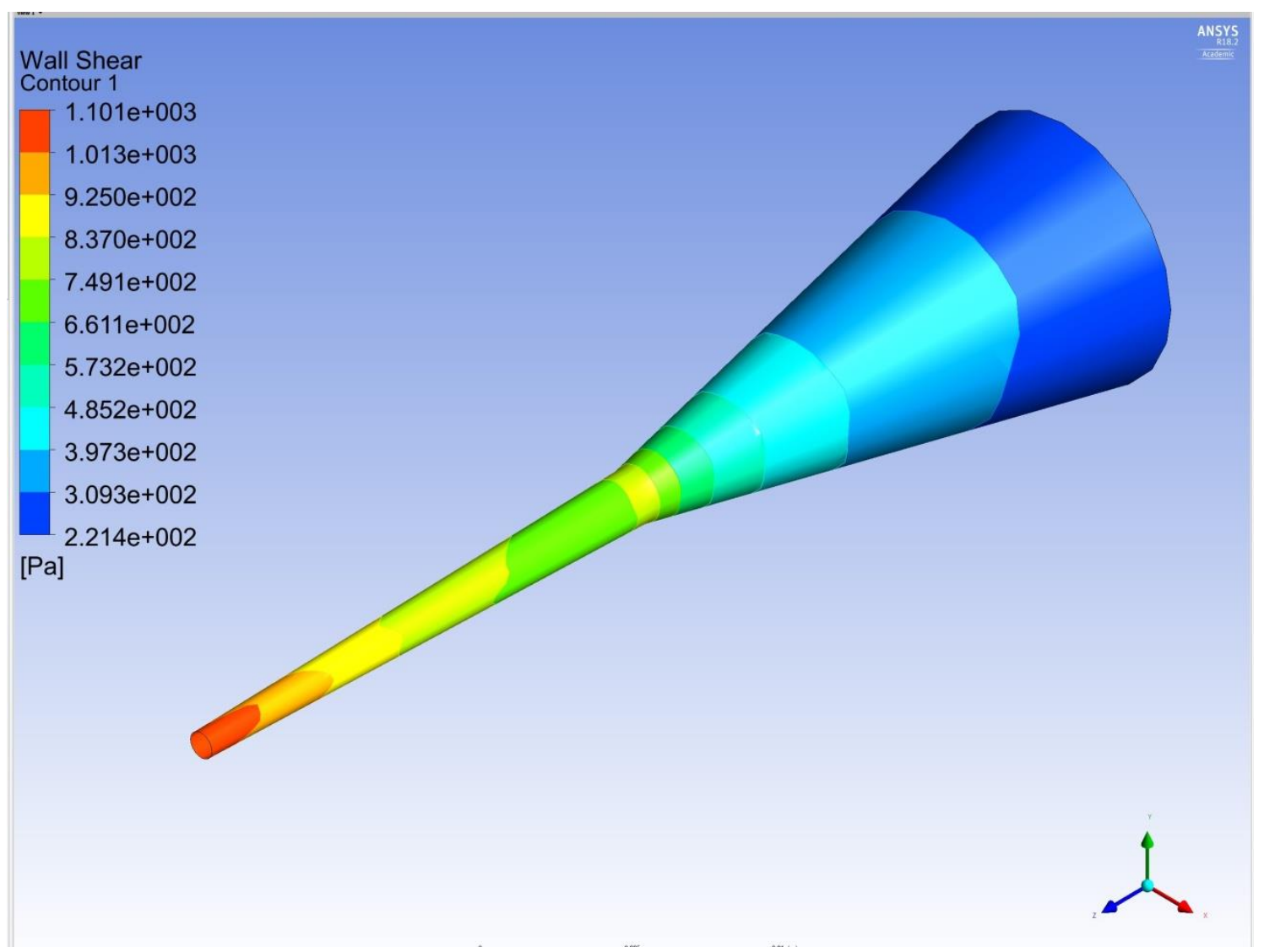

Figure 9: Wall shear contour plot for nozzle 8. 


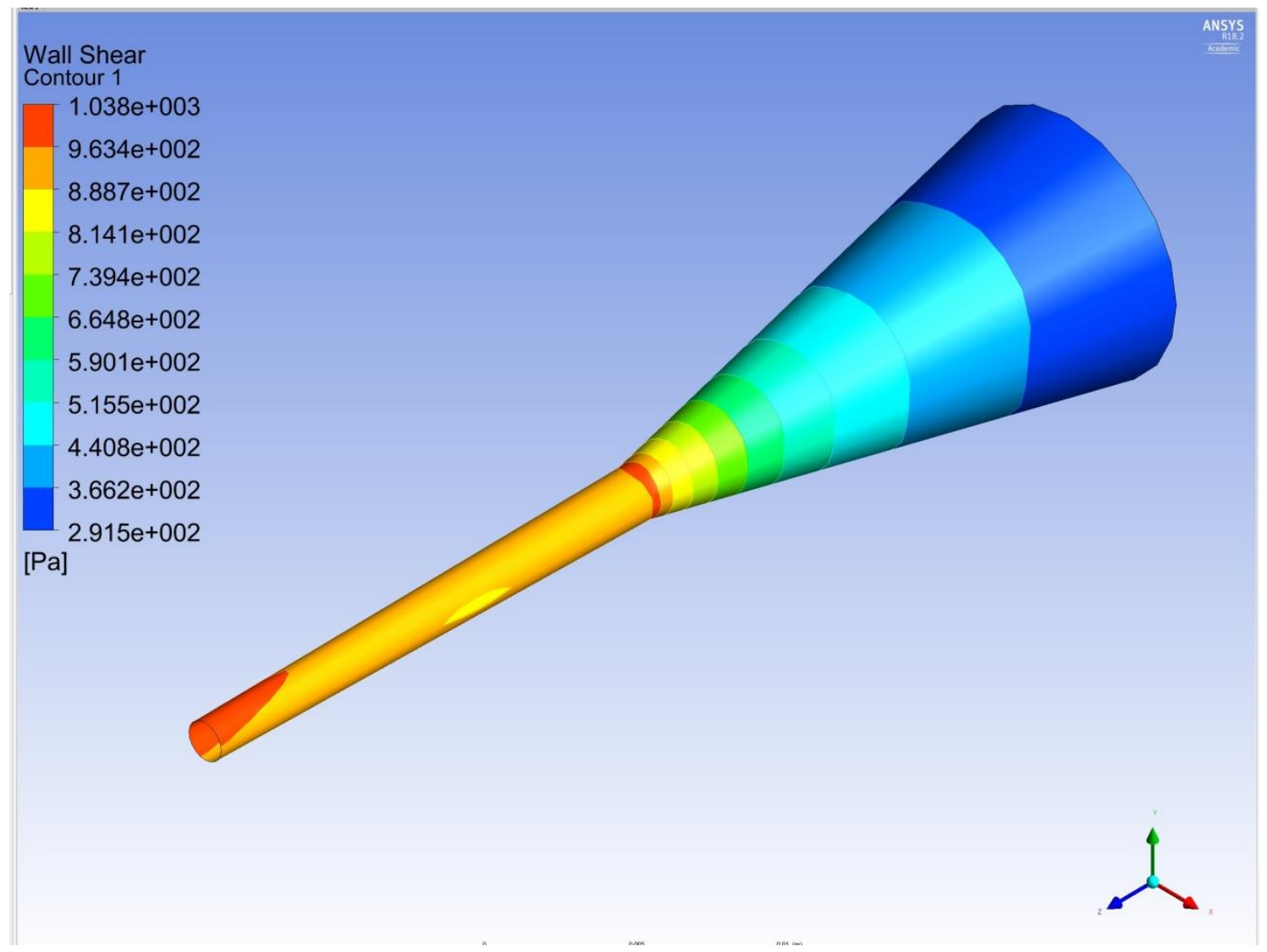

Figure 10: Wall shear contour plot for nozzle 9. 